\title{
A mobile application for assessing the product success on crowdfunding campaign: the development and usability testing
}

\author{
Yanti Pasmawati $^{12}$, Titis Wijayanto ${ }^{1 *}$, Alva Edy Tontowi ${ }^{1}$, Budi Hartono ${ }^{1}$ \\ ${ }^{1}$ Department of Mechanical and Industrial Engineering, Universitas Gadjah Mada, Jalan Grafika No.2, Yogyakarta 55284, Indonesia. \\ ${ }^{2}$ Department, of Industrial Engineering, Universitas Bina Darma, Jalan Jendral A Yani No.3, Palembang 30111, Indonesia.
}

\section{ARTICLE INFORMATION \\ Article history: \\ Received: December 2, 2021 \\ Revised: December 14, 2021 \\ Accepted: December 18, 2021}

Keywords:

POSCA application

Product success

Crowdfunding

User experience

USE questionnaire

\section{A B S T $\mathbf{T}$ A C $\mathbf{C}$}

Crowdfunding is one of the alternative sources of finance for product-based start-ups. Products are funded if the campaign is considered to be successful in reaching the target. The assessment of the success rate of product campaigns develops into three successive levels, namely overfunding, successful and unsuccessful. Due to the complication of setting up a product campaign on an online crowdfunding platform, a mobile application to aid campaigners needs to be developed. Moreover, it is essential to evaluate its ease to use. This study aims to (1) develop an android-based application, (2) evaluate the usability of the application based on user perceptions. The application ('POSCA') was developed by emphasizing user experience (UX), while the Use Questionnaire evaluated its usability. Ten participants were invited to evaluate the system usability and interface. The results suggest that 'POSCA' has good scores of usability: 'efficiency' $=49.11 \%$ in the fifth trial, 'very-easy-to-learn' (95\%), 'useful' (85\%), 'easy-to-use' $(87 \%)$, and 'satisfy-the-users' $(88 \%)$.

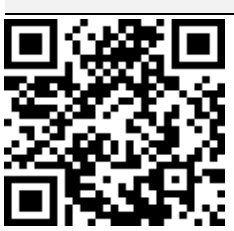

This is an open-access article under the CC-BY-NC-SA license.

Titis Wijayanto

E-mail: twijaya@ugm.ac.id

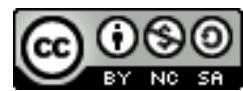

(C) 2021 Some rights reserved

\section{INTRODUCTION}

Crowdfunding is a new type of financing to help small and medium enterprises (SMEs), a nonprofit fund to realize ideas [1]. Crowdfunding offers an alternative platform and source of finance for projects [2]. In recent years, the development of online crowdfunding platforms has increased and has become a marketing tool [3]. One of the crowdfunding types is rewardbased. The presence of reward-based crowdfunding offers a fresh approach to obtaining a small amount of financial support and a small amount of financial support from many people (i.e. the crowd). Product success of a reward-based crowdfunding campaign is obtained when the product campaign reaches at least $100 \%$ of the funding target [4]. Achieving success in a crowdfunding campaign is not an easy task. For example, the success of the 'technology product' category on Kickstarter is only around 7.35\% [4] to $21.07 \%$ [5].

Several studies have carried out efforts to investigate product success and its determinants in a reward-based crowdfunding setting. For example, the identification of factors that influence the success of crowdfunding [6-9], the use of feedback as a stimulus for backers investment interest [10-12], as well as research on 
predicting models of crowdfunding campaign success [2,13-15].

The technology could aid would-be campaigners to assess the likelihood of product success in a crowdfunding campaign. Several studies which develop technology-based applications have been reported. For instance, a quantitative descriptive method used to determine the product success on a crowdfunding platform based on the favourite market quadrant is necessary [4]. Online customer reviews $\left(\mathrm{OCR}_{\mathrm{s}}\right)$ and Natural Language Processing (NLP) method have been used to find the value representation of each document in the corpus [9]. We have also discussed a technology product's success level instrument (overfunding, successful, unsuccessful) on the online crowdfunding platform. We used a classification model to determine the attribute class from text mining (online customer reviews) collected and multinomial logistic regression to assess success level achievement.

This study offers a follow-up work that focuses on translating findings from previous studies $[4,9]$ into a workable mobile application. This study urgency is the complexity of setting up a product campaign on an online crowdfunding platform, a mobile app to help campaigners need to be developed. In addition, to describe the design process, this study also reports the usability evaluation of the system. Usability has an international standard definition in ISO $9241 \mathrm{pt} 11$ (ISO, 2018), which defines usability as the extent to which specific users can use a product to achieve certain goals with effectiveness, efficiency, and satisfaction in specific contexts of use [16]. According to [17], a product or system is called usable to fulfil its efficiency, effectiveness, and satisfaction. This study's objectives are twofold, namely: (1) to develop an android-based 'POSCA' application, (2) to evaluate the application's usability based on user perceptions.

The application in this research is called POSCA'. 'POSCA' is a product performance appraisal application on an online crowdfunding platform. The 'POSCA' application is intended for users, especially startup businesses, to assess a product launched or distributed to the market and evaluate it before processing it into the production stage. This study employed User experience (UX) as experience information from product user interactions to develop 'POSCA' applications. The Usefulness, Satisfaction, Ease of Use (USE) Questionnaire method was used to measure the user's ability to use and perform tasks on the 'POSCA' application. The USE questionnaire is a questionnaire to measure user perceptions of the POSCA application. The Use Questionnaire has been used in several studies, such as to evaluate virtual assistance as a treatment provider for the elderly [18] and to test the usability of the Human Resource Information System (HRIS) user interface [19]. The USE questionnaire is a valid and reliable instrument [20]. Measurement of the USE questionnaire was carried out after the end of the task scenario session (post-test questionnaires). According to Lund [21], the USE questionnaire includes four category assessments: Usefulness, Satisfaction, Ease of Use, and Ease of Learning.

\section{RESEARCH METHODS}

This study consists of two stages: (1) design and development of the 'POSCA' application, (2) application usability testing.

\subsection{Application design and development}

'POSCA' application development employed a User Experience (UX) approach. Formative usability studies were used to design and develop the android-based 'POSCA' application. The stages of application development include gathering requirements, design analysis, setup database configuration, setup local development web admin/ android web view, development, review/update, deployment. The flow of the application development process is shown in Fig. 1.

The 'POSCA' application development used programming languages python 3.7 and several other tools. Java version 8 was used for mobile apps, and the Django app was used for the backend server. Software tools used for 'POSCA' application development, among others: Database (PostgreSQL); Android Studio (android application development IDE); VSCode (text editor: SublimeText, ATOM); Database editor (DBeaver); PuTTY (ssh webserver: MobaXterm). The 'POSCA' application was then stored in http://www.onlineprospectprediction.com. for download.

\subsection{Application Usability Testing}

\subsubsection{Participants}

This study invited ten participants as evaluators of the 'POSCA' application. The participants were seven males and three Females 
ranged between 25 and 40 years old (mean age 29). They were business actors (two participants), product development team members (five participants), and product marketing team members (three participants). All participants had no experience using the 'POSCA' application before they participated in the usability testing. The number of participants was sufficient as a sample size in the development of this application because it involves a group of users who have the same characteristics and thoughts on tasks and business goals [22].

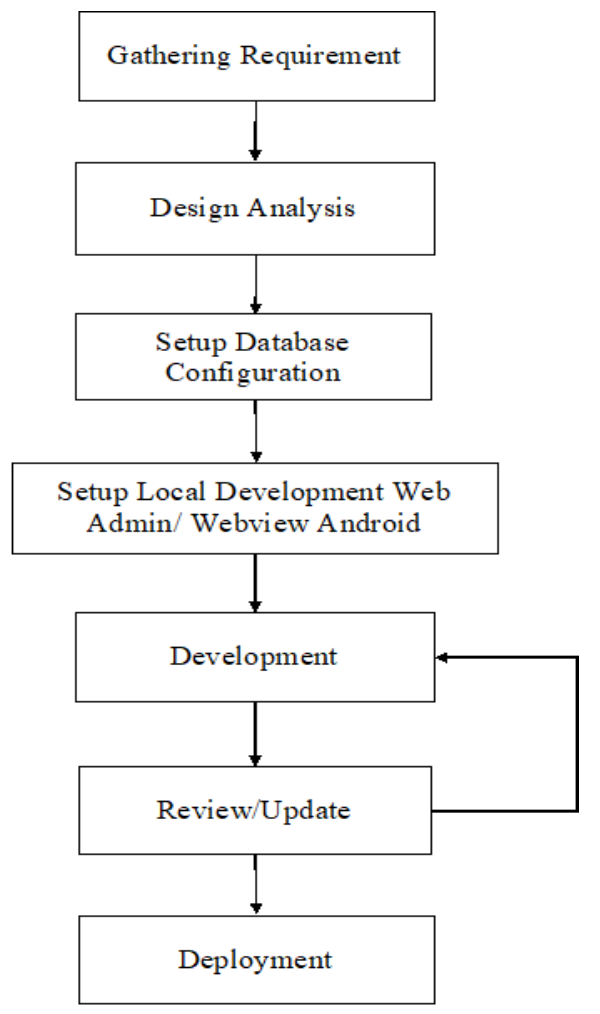

Fig. 1. Application development stages

\subsubsection{Testing protocol}

Before the main testing session, participants were introduced to the 'POSCA' application, the basic function, and how to operate the application. The participants were then asked to perform a series of tasks using the 'POSCA' application, as shown in Table 1. Participants were allowed to stop when they could not complete the task, and the test was then considered failed. After performing the tasks, participants were provided with a five-minute break before repeating the same tasks in the next session. The tasks were repeated five times with a five-minute break between the sessions to measure the learning curve.
Table 1. Tasks for usability testing on POSCA application

\begin{tabular}{cl}
\hline No. & \multicolumn{1}{c}{ Tasks } \\
\hline 1 & $\begin{array}{l}\text { Fill in the account (username and } \\
\text { password) }\end{array}$ \\
2 & $\begin{array}{l}\text { Perform language search and selection } \\
\text { and login }\end{array}$ \\
3 & $\begin{array}{l}\text { Do a menu search and understand the } \\
\text { app }\end{array}$ \\
4 & Do an assessment menu search \\
5 & Fill in startup business data \\
6 & $\begin{array}{l}\text { Search and select a model equation for } \\
\text { assessment according to the desired }\end{array}$ \\
7 & $\begin{array}{l}\text { prediction } \\
\text { Do attributes assessment }\end{array}$ \\
8 & $\begin{array}{l}\text { Search product campaign assessment } \\
\text { results }\end{array}$ \\
9 & $\begin{array}{l}\text { Search and choose the history of product } \\
\text { campaign assessments that have been } \\
\text { carried out }\end{array}$ \\
10 & Log out \\
\hline
\end{tabular}

\subsubsection{Usability measurements}

Usability evaluation on POSCA application development measured two UX metrics, performance metrics and self-reported or satisfaction metrics. Performance measurement was used to determine the extent to which the user could complete the task. The performance metrics used in this study were success rate, completion time and learnability. The success rate was measured in the percentage of participants who completed the tasks correctly [17]. The completion time was measured as the calculated time required to complete each task and was then used to measure efficiency. The efficiency measured in this study is the efficiency of optimal learning abilities from five trials.

The USE questionnaire was used to measure the subjective satisfaction level. This questionnaire uses a seven-point Likert scale. The items in the questionnaire are positive sentences and a scale of 1 (strongly disagree) to 7 (strongly agree). The larger the scale, the higher the weight of the assessment. The Use Questionnaire is broad and non-proprietary and can be accessed at Gary Perlman's website [23].

\section{RESULTS AND DISCUSSION}

The 'POSCA' application was designed and developed based on user experience (UX). In general, the 'POSCA' application operating system 
consists of three stages of the process: (1) data entry for startups businesses; (2) product attribute assessment; (3) the results of product performance assessment on the online crowdfunding platform. The process of operating the application is shown in Fig. 2.

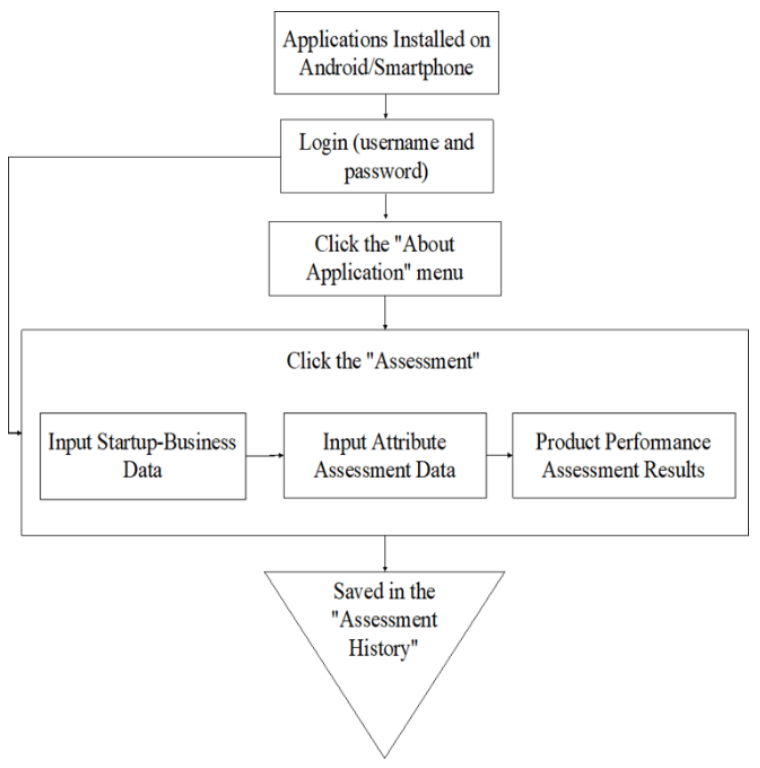

Fig. 2. 'POSCA' application operation process

Data entry begins with the login process using each users account. Page 1, equipped with a forgot password facility if the user experiences an account typing error. This application uses two languages, Indonesian and English (Fig. 3). Page 2 displays the menu provided in the application as information and the product performance assessment process (Fig. 4). The application menu is divided into three sections: application, assessment, assessment history (Fig. 4).
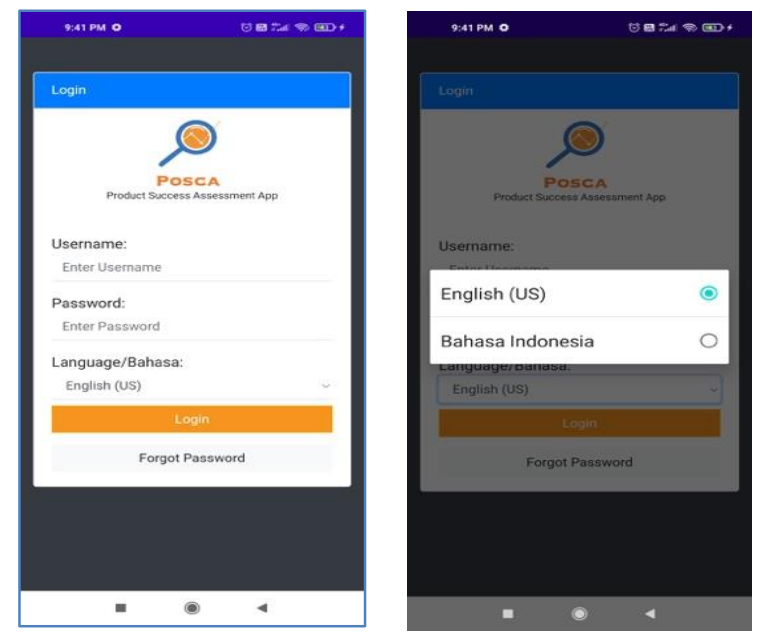

Fig. 3. Login page view

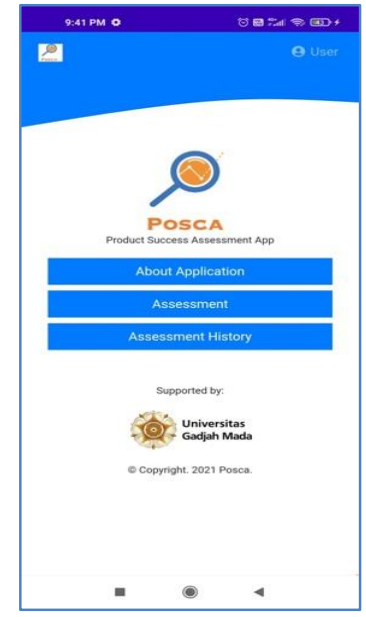

Fig. 4. Menu page interface on 'POSCA' application

The "about application" menu contains essential information to facilitate user understanding in using the application. The information on this menu consists of (1) the intent and purpose of using the application, (2) understanding and explanation of the attributes of the product performance assessment, (3) the rating scale for each attribute, (4) the assessment score along with information on the level of product success performance in online crowdfunding platform. The interface of this menu can be seen in Fig. 5.

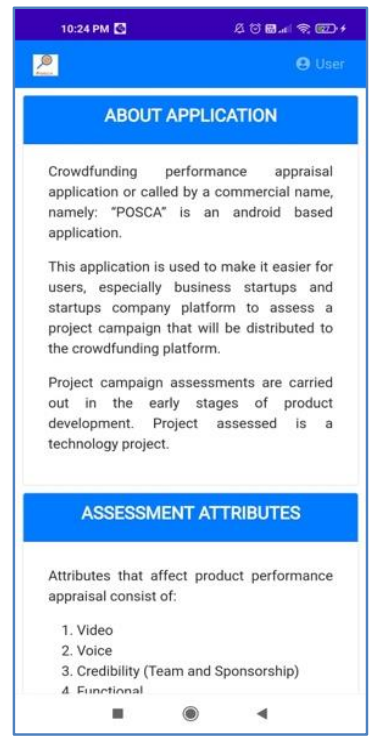

Fig. 5. The interface of the about application menu

The "Assessment" menu consists of startups business data, attribute assessment and product performance assessment results. The data entry page requires the user to input data on the startup's 
name, the type of product, the time of the assessment, and the formula selection for the performance appraisal model. The product performance appraisal has two assessments, Model 1 to assess the level of unsuccessful and successful performance and Model 2 to assess the performance of not successful and very successful. The choice of these models depends on the user's goals for the desired assessment. The interface of the data entry page is shown in Fig. 6.

The attribute rating page includes all the attributes that affect the successful performance of crowdfunding. This attribute assessment is in the form of numeric and categorical data. An explanation of the questions related to attributes is shown in each question, as shown in Fig. 6. The rating attributes with a numerical rating scale are the question/rating attributes for video, voice, comments, positive reviews, and negative reviews. At the same time, the rating scale is in the form of categories, namely credibility, functional, service. The questions listed on this page menu must be answered: the calculation or assessment process cannot be continued before all questions are answered.

This page is information on the assessment results that have been carried out in the previous stage. Fill in the information in the form of startups business data, response value (performance), performance level, and display data in the form of a chart, as shown in Figure 6. This interface explains the results of the assessment of whether product performance on the online crowdfunding platform is declared unsuccessful or successful or very successful. These results can be considered for startup businesses in making decisions for the following production process or other commercial strategies.

The results of product performance assessments are stored in the assessment history menu so that users can review product performance assessments that have been carried out previously. The display of the assessment history menu is shown in Fig. 7. This interface also has a search menu to facilitate users in disbursing startups business assessment data.

The interface of the assessment history menu The design and development results of this 'POSCA' application were then tested to evaluate the application usability based on the experience of the interaction between users and the 'POSCA' application.
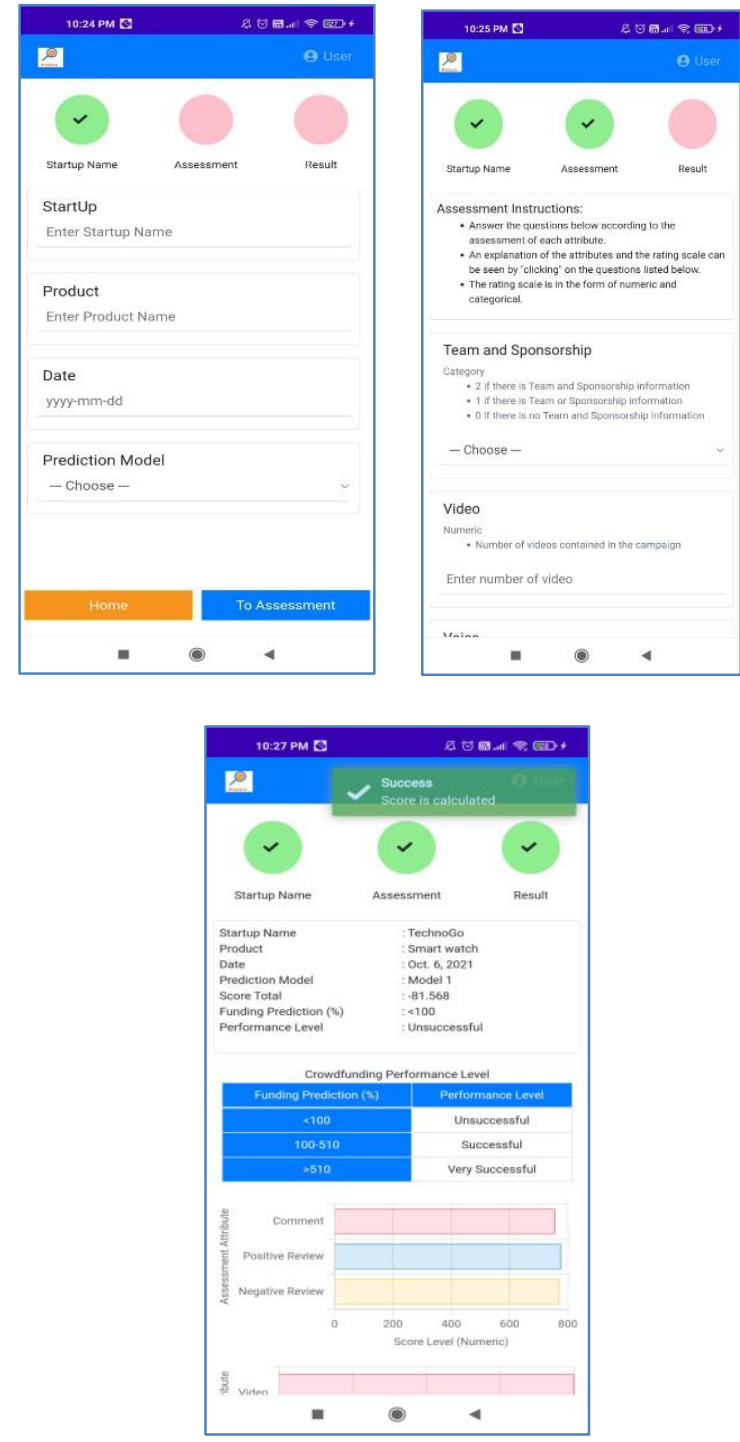

Fig. 6. The interface of the assessment menu

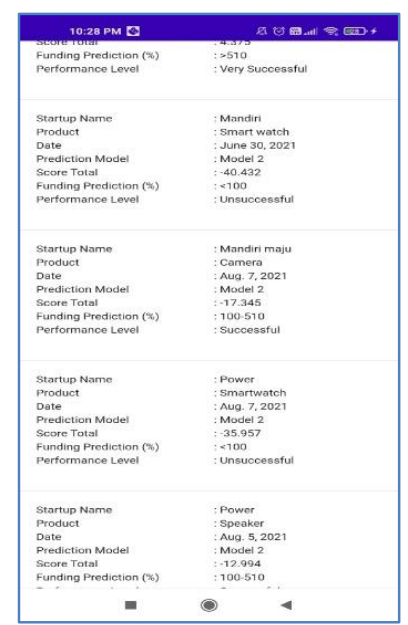

Fig. 7. The interface of the assessment history menu 


\subsection{Usability testing results \\ 3.1.1. Success rate}

The success rate measured how effectively participants completed a series of tasks shown in Table 1 . The usability test results showed that ten tasks could be completed to the maximum without any task completion failure indicating that the success rate for the 'POSCA' application per task is $100 \%$. The success rate shows that the 'POSCA' application is effortless, and participants' understanding is very good.

\subsubsection{Completion time analysis}

Completion time was used to measure how much time it takes to complete a task (Table 1). The completion time of the tasks is shown in Fig. 8.

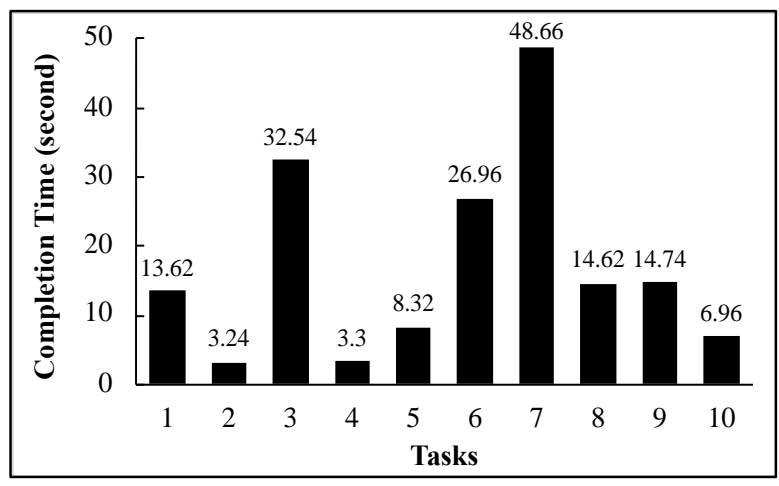

Fig. 8. Completion time per task

The completion time for each task is different, and this difference is influenced by the type of task and the effort made to complete the task. The completion time per task was obtained from the average completion time of ten participants with five trials. Fig. 8 shows that the task that requires great effort is task-7, followed by task- 3 , task- 6 , and the effortless is task- 2 .

\subsubsection{Efficiency analysis}

Efficiency was measured by the number of actions required to complete a task; efficiency is also the ratio of the success rate of a task to the average completion time per task. Operations in completing tasks in the 'POSCA' application have efficiency dynamics. However, the 'POSCA' application can efficiently assess products both per task and overall task completion. Fig. 9 shows the percentage efficiency of completing time per task.

The maximum efficiency in the 'POSCA' application reaches $58 \%$, which is the completion of task-10. On the other hand, the smallest efficiency is $9 \%$, which is the completion of the task to 9 . The efficiency of each task varies. This variation is due to the effort and action were taken in carrying out each user's task. Efficiency data is analyzed and presented based on the number of actions taken to complete the task. The task average is calculated to find out how many actions are taken. It is also used to identify the task that has the most effort.

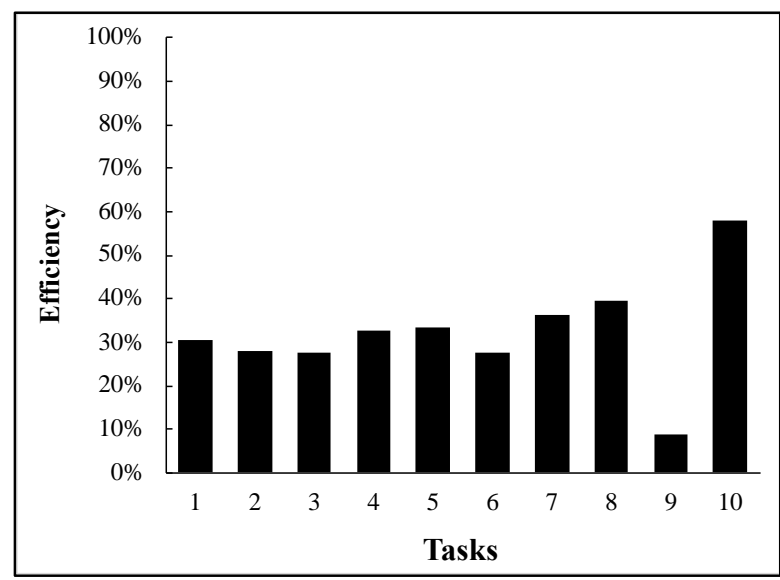

Fig. 9. Efficiency based on task completion time

\subsubsection{Learnability analysis}

Learnability was used to test participants' learning abilities using the 'POSCA' application. Learnability considers how easy it is for participants to complete the first task and how many trials it takes to be proficient and efficient. User experience metrics based on completion time per trial in operating the 'POSCA' application based on the assigned task scenarios are shown in Fig. 10 and Fig. 11.

The learning curve in Fig. 10 and Fig. 11 shows a plot of all tasks' completion times per trial (repetition of tasks). The completion time on the first try reaches the highest peak on the graph line and has the longest settlement time. The subsequent trials (trials 2, 3, 4, 5) decreased and reached the ideal slope of the graph. Learnability discusses how the efficiency of performing tasks changes from time to time, resulting in maximum performance time. The data shows a significant increase in completion time from trial 1 to trial 2.

Furthermore, the increase in completion time still occurs, but the gap is small and is shown by a horizontal timeline graph. However, there is a dynamic of time in the trials per task. Based on this explanation, it is concluded that learning in the 'POSCA' application occurs quickly and achieves maximum performance time in trial 5 . 
The decrease in completion time reaches $50.89 \%$ from the first trial of task implementation, and overall task efficiency is $49.11 \%$. Based on the explanation described above, the efficiency of $49.11 \%$ is the efficiency of users' optimal learning ability in using the 'POSCA' application for the five trials.

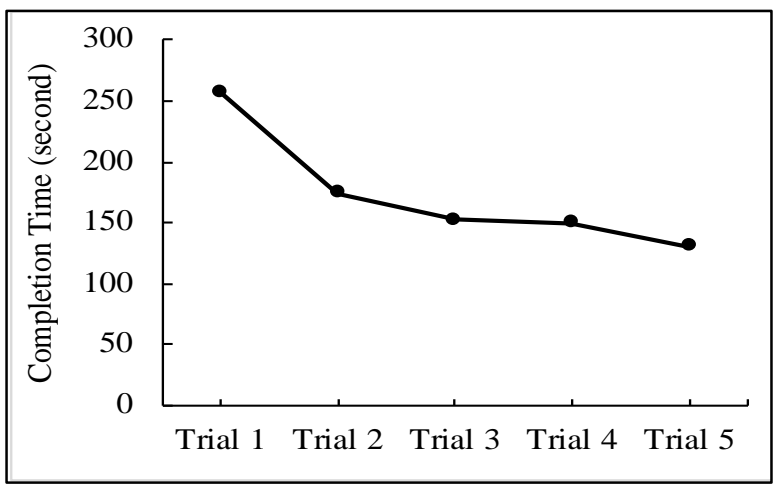

Fig. 10. Learnability data based on time on task

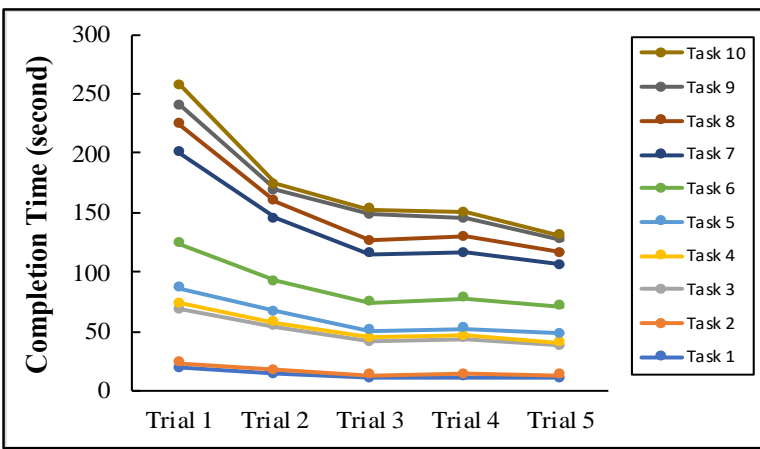

Fig. 11. Learnability curve from several trials

\subsubsection{USE questionnaire analysis}

The USE questionnaire uses a seven-point Likert scale. The items in the questionnaire are positive statements and a scale of 1 (strongly disagree) to 7 (strongly agree). The larger the scale, the higher the weight of the assessment.

The Cronbach Alpha test on the results of the USE Questionnaire from ten users shows that there is consistency in all user answers. This is indicated by the value of the coefficient of determination of 0.97 . This coefficient value is more significant than 0.60 , indicating the Use Questionnaire were reliable for measuring research variables. A total of 30 questions from the four dimensions of the Use Questionnaire, namely usefulness, ease of use, ease of learning, and satisfaction, have been collected. The results of the answers from the users are shown in Table 2.
Table 2. Recapitulation of scores from the USE questionnaire

\begin{tabular}{|c|c|}
\hline Questions & Score \\
\hline \multicolumn{2}{|l|}{ Usefulness } \\
\hline - It helps me be more effective & 6.30 \\
\hline - It helps me be more productive & 6.30 \\
\hline - It is useful & 6.30 \\
\hline $\begin{array}{l}\text { - It gives me more control over the } \\
\text { activities in my life }\end{array}$ & 6.30 \\
\hline $\begin{array}{l}\text { - It makes the things I want to accomplish } \\
\text { easier to get done }\end{array}$ & 5.80 \\
\hline - It saves me time when I use it & 6.50 \\
\hline - It meets my needs & 5.00 \\
\hline $\begin{array}{l}\text { - It does everything I would expect it to } \\
\text { do }\end{array}$ & 5.00 \\
\hline \multicolumn{2}{|l|}{ Ease of Use } \\
\hline - It is easy to use & 6.40 \\
\hline - It is simple to use & 6.40 \\
\hline - It is user friendly & 6.40 \\
\hline $\begin{array}{l}\text { - It requires the fewest steps possible to } \\
\text { accomplish what I want to do with it }\end{array}$ & 5.70 \\
\hline - It is flexible & 6.40 \\
\hline - Using it is effortless & 6.40 \\
\hline - It can use it without written instructions & 5.30 \\
\hline $\begin{array}{l}\text { - I don't notice any inconsistencies as I } \\
\text { use it }\end{array}$ & 5.50 \\
\hline $\begin{array}{l}\text { - Both occasional and regular users } \\
\text { would like it }\end{array}$ & 6.30 \\
\hline $\begin{array}{l}\text { - I can recover from mistakes quickly and } \\
\text { easily }\end{array}$ & 6.30 \\
\hline - I can use it successfully every time & 5.70 \\
\hline \multicolumn{2}{|l|}{ Ease of Learning } \\
\hline - I learned to use it quickly & 6.60 \\
\hline - I easily remember how to use it & 6.70 \\
\hline - It is easy to learn to use it & 6.60 \\
\hline - I quickly became skilful with it & 6.60 \\
\hline \multicolumn{2}{|l|}{ Satisfaction } \\
\hline - I am satisfied with it & 6.20 \\
\hline - I would recommend it to a friend & 6.70 \\
\hline - It is fun to use & 6.10 \\
\hline - It works the way I want it to work & 5.40 \\
\hline - It is wonderful & 6.10 \\
\hline - I feel I need to have it & 6.70 \\
\hline - It is pleasant to use & 6.10 \\
\hline
\end{tabular}

The measurement results on the 'POSCA' application show that the average value for the usefulness dimension is 5.94, ease of use is 6.07, ease of learning is 6.63, and satisfaction is 6.19 . The value of all these dimensions exceeds the average value, which means that the 'POSCA' application provides user satisfaction, is easy to use and useful. The highest score on the ease of learning dimension shows that the 'POSCA' 
application is effortless to learn for users to assess products.

The used questionnaire also shows the critical point of the 'POSCA' application. As in Table 2, the lowest assessment and the most critical point is in the usefulness dimension. The 'POSCA' application has not met all the needs and is per user expectations. Some users even think that this needs to be developed again to fulfil all related product assessments. The ease of use dimension also shows that the user still experiences errors in some actions even though all processes of operating the 'POSCA' application have been successfully carried out.

It technically occurred during a login error because the username was invalid, which might be due to a typo or typo. Furthermore, it is necessary to improve the time setting of the assessment because it does not automatically change when selected, so errors often occur. The critical point on the ease of use dimension is also found in the product assessment process, so it is necessary to improve the instructions and steps in achieving the final product assessment result. The satisfaction dimension states that the user is very satisfied using the 'POSCA' application. However, the 'POSCA' application needs to be improved and facilitated according to the user's wishes.

In addition, a radar graph was used to determine the assessment pattern of the 'POSCA' application based on the results of the Use questionnaires, as shown in Fig. 12.

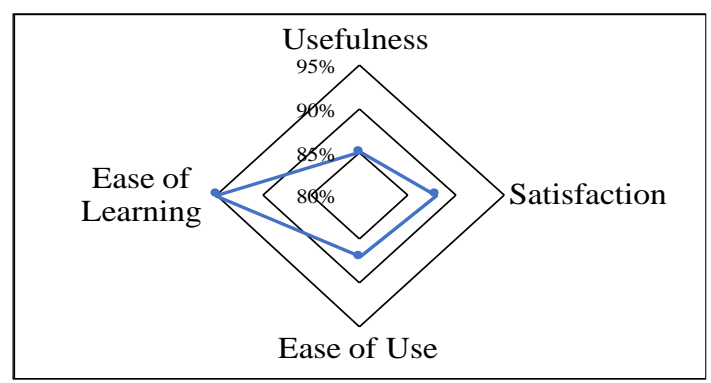

Fig. 12. Data visualization of the use questionnaire

The radar graph shows that the usefulness percentage value is $85 \%$, ease of learning is $95 \%$, satisfaction is $88 \%$, and ease of use is $87 \%$. In addition, based on the pattern formed on the radar graph, the 'POSCA' application is effortless to learn, easy to use, satisfying, and useful for users to evaluate products. In terms of increasing the dimensions of each other, it is also known that
Ease of Use and Usefulness on 'POSCA' application are correlated with each other. The increase in the value of ease of use and usefulness also encourages an increase in users' satisfaction. The ease of use assessment for users contribution from the two value dimensions, namely ease of learning and ease of use which is highly correlated with the operation of the 'POSCA' application.

\section{CONCLUSION}

The study results conclude that the 'POSCA' application developed with a user experience (UX) approach is an android-based application to assess technology products on a usable online crowdfunding platform. The usability test evidence this; it is shown that the efficiency of the operation of all tasks in the 'POSCA' application for users reaches $49.11 \%$. The operational stability of the POSCA application started on trials 3, 4, and 5 and reached the maximum performance time after five trials. The curve dynamic also occurs because if there are many repetitions of product assessments, the data or information will increase and cause user interest to find out the information so that the speed of task completion time decreases. The usability test based on the Use Questionnaire also concluded that the 'POSCA' application is an application that is very easy to learn (95\%), usefulness (85\%), easy to use (87\%), and satisfaction (88\%) to assess technology products.

In particular, it is expected to meet the needs and desires of users to assess the product and technically improve the 'POSCA' operation system so that it is easier for users to use 'POSCA' and the level of user satisfaction increases as it is known that ease of use and usefulness influence each other, and these two dimensions can affect the level of user satisfaction in a product. Future research is expected to use the critical findings in this study to develop 'POSCA' applications and increase the efficiency score. It can also discuss the learning curve issue due to the relatively new 'POSCA' application.

\section{REFERENCES}

[1] H. Li, X. Chen, Y. Zhang, and M. Hai, "Prediction of Financing Goal of Crowdfunding Projects," Procedia Comput. Sci., vol. 139, pp. 108-113, 2018, doi: 10.1016/j.procs.2018.10.225.

[2] B. Hartono, I. Tantina, and B. S. Wibowo, 
"Exploring Successful Campaign Profiles On Crowdfunding-Based Project Financing: A Tree-Based Comparative Analysis," Int. J. Innov. Manag., vol. 2150041, pp. 1-38, 2021, doi: $10.1142 / \mathrm{S} 1363919621500419$.

[3] T. E. Brown, E. Boon, and L. F. Pitt, "Seeking funding in order to sell: Crowdfunding as a marketing tool," Bus. Horiz., 2016, doi: 10.1016/j.bushor.2016.11.004.

[4] Y. Pasmawati, A. E. Tontowi, B. Hartono, and T. Wijayanto, "Determination of Favourite Market for 3D-Printer Product Based Online Platform, " Int. Rev. Manag. Mark., vol. 8, no. 5, pp. 18-23, 2018, doi: 10.32479/irmm.6906.

[5] Kickstarter, "Kickstarter Stats," Stats, 2021.

Available:

https://www.kickstarter.com/help/stats (accessed January 13, 2018).

[6] H. Yuan, R. Y. K. Lau, and W. Xu, "The Determinants of Crowdfunding Success: A Semantic Text Analytics Approach Department," Decis. Support Syst., 2016, doi: 10.1016/j.dss.2016.08.001.

[7] S. Bi, Z. Liu, and K. Usman, "The influence of online information on investing decisions of reward-based crowdfunding 弥," J. Bus. Res., vol. 71, pp. 10-18, 2017, doi: 10.1016/j.jbusres.2016.10.001.

[8] L. Z. Xu, "Will a digital camera cure your sick puppy? Modality and category effects in donation-based crowdfunding," Telemat. Informatics, vol. 35, no. 7, pp. 1914-1924, 2018, doi: 10.1016/j.tele.2018.06.004.

[9] Y. Pasmawati, A. Edy Tontowi, B. Hartono, and T. Wijayanto, "Exploiting online customer reviews for product design, " IOP Conf. Ser. Mater. Sci. Eng., vol. 909 , no. 1, 2020, doi: 10.1088/1757899X/909/1/012080.

[10] X. Li, C. Wu, and F. Mai, "The effect of online reviews on product sales: A joint sentiment-topic analysis," Inf. Manag., vol. 56, no. April 2018, pp. 172-184, 2019, doi: 10.1016/j.im.2018.04.007.

[11] K. Bafna and D. Toshniwal, "FeatureBased Summarization of Customers
Reviews of Online Products," Procedia Procedia Comput. Sci., vol. 22, pp. 142 151, 2013, doi: 10.1016/j.procs.2013.09.090.

[12] R. Ireland and A. Liu, "Application of data analytics for product design: Sentiment analysis of online product reviews," CIRP J. Manuf. Sci. Technol., vol. 23, pp. 128144, 2018, doi: 10.1016/j.cirpj.2018.06.003.

[13] J. C. Kaminski and C. Hopp, "Predicting outcomes in crowdfunding campaigns with textual, visual, and linguistic signals," Small Bus. Econ., vol. 55, no. 3, pp. 627649, 2020, doi: 10.1007/s11187-01900218-w.

[14] S. H. Lee, H. Chul Kim, and K. H. Lee, "Content-based success prediction of crowdfunding campaigns: A deep learning approach," Proc. ACM Conf. Comput. Support. Coop. Work. CSCW, pp. 193196, 2018, doi: $10.1145 / 3272973.3274053$.

[15] Q. Zhang, T. Ye, M. Essaidi, S. Agarwal, V. Liu, and B. T. Loo, "Predicting startup crowdfunding success through longitudinal social engagement analysis," Int. Conf. Inf. Knowl. Manag. Proc., vol. Part F1318, pp. 1937-1946, 2017, doi: 10.1145/3132847.3132908.

[16] ISO/IEC, "ISO 9241-11:2018(en), Ergonomics of human-system interaction - Part 11: Usability: Definitions and concepts," Iso. p. 9241(11), 2018. Available:

https://www.iso.org/obp/ui/\#iso:std:iso:92 41:-11:ed-2:v1:en.

[17] J. Nielsen, "Usability Engineering," Academic Press, Inc., United Kingdom, p. 240, $1994 . \quad$ Available: https://books.google.co.id/books?id=95As 2OF67f0C.

[18] A. L. Jegundo et al., "Perceived Usefulness, Satisfaction, Ease of Use and Potential of a Virtual Companion to Support the Care Provision for Older Adults," Technologies, vol. 8, no. 3, p. 42, 2020, doi: 10.3390/technologies8030042.

[19] D. Prastyo, S. Udin, and M. Y. Bakhtiar, "Development of the Human Resources Information System (HRIS) Based on 
Usability Analysis with Usefulness, Satisfaction, Ease to Use (USE) Questionaire and Cognitive Walkthrough Methods," bit-Tech, vol. 1, no. 3, pp. 150162, 2019, doi: 10.32877/bt.v1i3.77.

[20] M. Gao, P. Kortum, and F. Oswald, "Psychometric evaluation of the USE (usefulness, satisfaction, and ease of use) questionnaire for reliability and validity," Proc. Hum. Factors Ergon. Soc., vol. 3, no. September, pp. 1414-1418, 2018, doi: 10.1177/1541931218621322.

[21] A. M. Lund, "Measuring usability with the use questionnaire," Usability interface, vol. 8, no. 2, pp. 3-6, 2001. Available: https://www.researchgate.net/publication/ 230786746.

[22] B. Albert and T. Tullis, Measuring the User Experience: Collecting, Analyzing, and Presenting Usability Metrics. Elsevier Science, 2013. Available: https://books.google.co.id/books?id=bPhL eMBLEkAC.

[23] A. Lund, "USE Questionnaire: Usefulness, Satisfaction, and Ease of use," Hcibib.Org, 2008.

Available: http://garyperlman.com/quest/quest.cgi?fo $\mathrm{rm}=\mathrm{USE}$. 